\title{
Whither Stem Cell Biology?
}

\author{
Steven W. Levison, Hershey, Pa. \\ Richard S. Nowakowski, Piscataway, N.J.
}

In the best of worlds, the clinician of the future will be able to repair an injury to the CNS with an armamentarium of therapies. Undoubtedly, included in this will be 'magic bullets' to replace lost cells in specific and functionally constructive ways. The key to finding such therapies may lie in the burgeoning field of stem cell biology. Stem cell research has dramatically increased over the last few years. In recent years, stem cells and their close kin 'progenitor cells' and 'precursor cells', all of which have long been of interest to developmental neurobiologists, have captured the attention of a larger contingent of neuroscientists because of their expected therapeutic potential. In the future, for example, it is hoped (and indeed planned by some) that neural stem cells will be harvested, expanded in vitro and used for heterologous or homologous transplantation to treat injuries or cure degenerative diseases of the CNS. Alternatively, genetically engineered stem cells could be used to correct neurological diseases caused by genetic mutations. Perhaps the most challenging, but most attractive exploitation of stem cells would be to learn how to re-activate latent stem cells in the adult brain to effect repair and regeneration of damaged or degenerated circuits.

It has long been known that neurogenesis continues in discrete and particular areas of the adult mammalian brain. Recent demonstrations that multipotential progenitors can be propagated and differentiated in vitro have catalyzed the recent revival in CNS stem/progenitor cell research. Anticipating that research on neural stem cells is a growing discipline (pun intended!) and that development and regeneration are presumably closely related,

\begin{tabular}{ll}
\hline KARGER & ( 2000 S. Karger AG, Basel \\
0378-5866/00/0222-0005\$17.50/0 \\
$\begin{array}{l}\text { Fax +4161306 1234 } \\
\text { E-Mail karger@karger.ch } \\
\text { www.karger.com }\end{array}$ & $\begin{array}{l}\text { Accessible online at: } \\
\text { www.karger.com/journals/dne }\end{array}$
\end{tabular}

the editors of Developmental Neuroscience solicited articles for this Special Issue on 'Stem Cells and Progenitors' to advance our understanding of the cellular and molecular properties of the germinal matrices of the CNS, and the stem cells and progenitors they harbor. Of special interest were original articles that added to our knowledge of the progenitors in the forebrain ventricular and subventricular zones. The goal was to publish a volume containing high-quality enduring articles, that would highlight established or emerging areas of stem/progenitor cell research. The editors' and publisher's goal was to draw attention to this relatively immature field of study. Despite the fact that new findings in this field garner the attention of the popular media and that review articles appear almost monthly in neuroscience journals, the topic is still timely. Importantly, no single journal has yet emerged as the vehicle for publishing studies on CNS stem cells and progenitors. Beginning with this special issue, Developmental Neuroscience is uniquely poised to become that vehicle, and we hope that Developmental Neuroscience becomes a destination for articles reporting important revelations about neural stem cells and progenitors.

Figure 1 shows a simplistic diagram of the stem/progenitor cells in the germinal matrices of the forebrain. It depicts the two chief germinal zones of the brain, the ventricular zone (VZ) and the subventricular zone (SVZ). As shown, cells in the VZ are radially oriented, whereas SVZ cells are tangentially oriented with reference to the ventricle. In addition, it depicts the interkinetic movement of the nuclei of $\mathrm{VZ}$ cells, which is not characteristic
Steven W. Levison, $\mathrm{PhD}$

Neuroscience and Anatomy, H109

Penn State College of Medicine

PO Box 850, Hershey, PA 17033 (USA)

Tel. +1 717531 8650, Fax +1 717531 0714, E-Mail slevison@psu.edu 


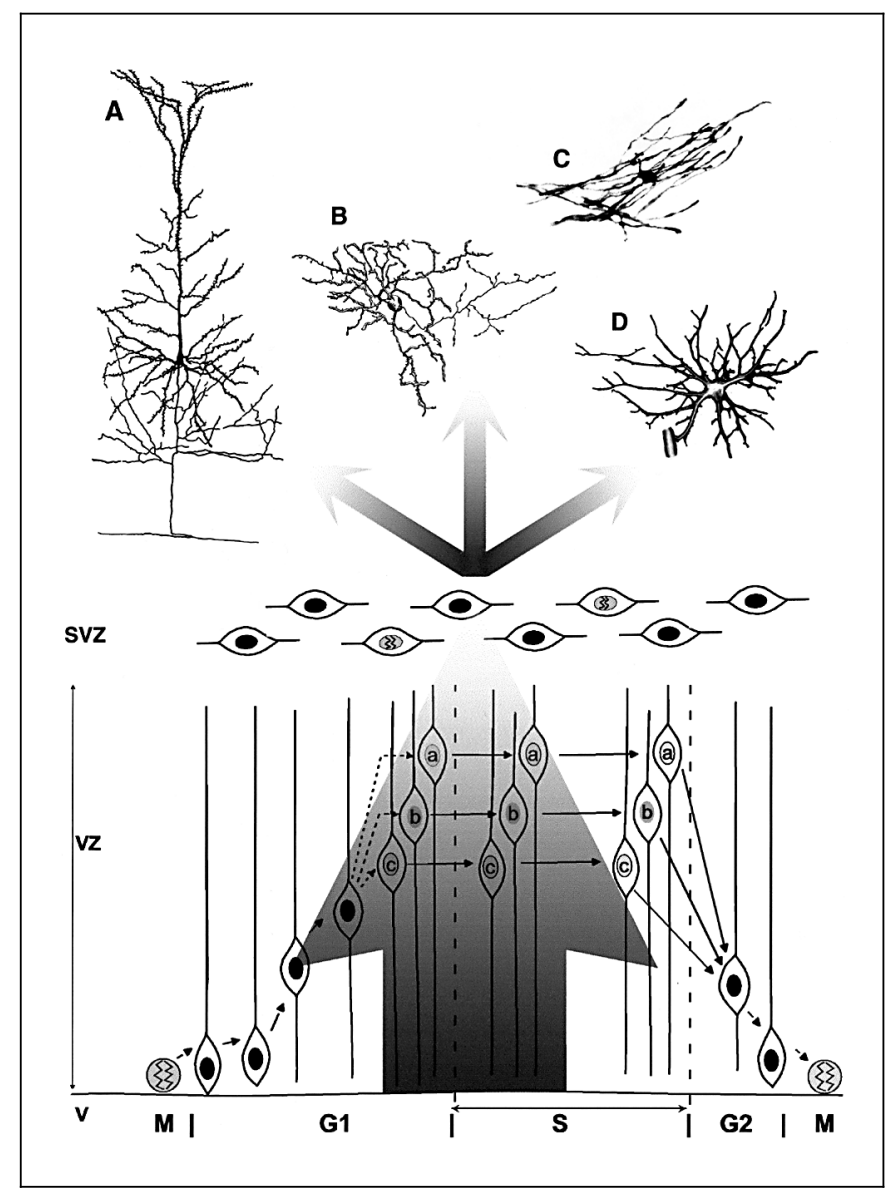

Fig. 1. A highly schematic diagram of the stem/progenitor cells in the two chief proliferative regions of the forebrain and the cell types they produce. The cells in the ventricular zone (VZ) comprise a pseudostratified columnar epithelium. As such, they undergo interkinetic nuclear movements, dividing at the ventricular surface, moving away from and then back to the surface during each pass through the cell cycle. The relationship of these movements to the phases of the cell cycle (M, G1, S, G2) is depicted. Overlying the pseudostratified cells of the $\mathrm{VZ}$ are the subependymal cells of the subventricular zone (SVZ). The large arrow symbolizes the largely radial migration of neuronal and glial progenitors/precursors into the developing forebrain. The 3 smaller arrows symbolize the differentiation and dispersal of these migrating cells into a variety of mature cell types, represented here by pyramidal neurons (A), spiny stellate neurons (B), oligodendrocytes (C), and astrocytes (D). Note that this general scheme varies substantially in different subdivisions of the forebrain. For example, in the striatum the SVZ is considerably larger than the VZ whereas the SVZ per se is undetectable in the hippocampus. Thus, this diagram is by no means meant to be comprehensive or to suggest or imply specific lineage relationships. of SVZ nuclei. During CNS development, the cells in the VZ and SVZ proliferate to reproduce themselves, and, most importantly, they produce neurons and glia of various types. These 'ur-stem cells' (i.e., the original multipotential proliferative cells of the brain) do this in a remarkably reproducible and precise fashion resulting in the marvel that is the mature brain. Cells with the properties of stem cells have been isolated from both the VZ and SVZ, as have cells with more restricted capacities and potential that are generally known as progenitors and precursors. It remains to be established how many different types of stem/progenitor cells exist in the CNS or indeed if there is a true 'omnipotential stem cell'. Indeed, it is likely that stem cells vary both in space (i.e. stem cells from different regions have different potentials) and in time (i.e., stem cells prepared at different stages of maturity have different potentials). This brings the single caution of our foreword: the term 'stem cell' is a relative one and is used conservatively by some authors and loosely by others. This difference in usage reflects in part how little neuroscientists actually know about the fates, capacities, and potentials of the proliferating cells that populate the germinal matrices and in part the relative optimism and/or pessimism each neuroscientist harbors. Eventually, the terms stem cells, progenitors, and precursors of the nervous system will need to be defined on objective bases that can be justified both on conceptual and experimental grounds. This challenge is being met by the growing community of neuroscientists interested in these cells, many of whom have contributed papers to this volume.

The editors of this special issue would like to express their appreciation to the authors for contributing noteworthy articles and to the reviewers for their constructive comments on the many submissions. We are pleased with the final product. Research on neural stem cells and progenitors has rapidly advanced and continues to do so, and surely many important discoveries have yet to be made. Hence, we believe that it is likely that this special issue will be the first of a series to be published every few years. We encourage you to contribute your best work related to stem cells and progenitors to Developmental Neuroscience so that this journal can continue its development as a destination for groundbreaking articles in this important specialty. 